\title{
Knowledge, attitude and practices on family planning services among adolescents in secondary schools in Hai District, northern Tanzania
}

\author{
CELINA M. DANGAT and BERNARD NJAU* \\ Kilimanjaro Christian Medical University College, Community Health Department, Moshi, Tanzania
}

\begin{abstract}
Almost $65 \%$ of the Tanzanian population is under the age of 24 and almost $20 \%$ of the population is aged 15-24 years. Yet, this important group faces many significant health challenges, such as early sexual debut, early pregnancies, risky behaviours and sexually transmitted infections. The objective of this study was to assess knowledge, attitudes and practices on family planning services among adolescents in secondary schools in Hai District in northern Tanzania. A cross sectional study was conducted between April and June 2011 among 316 randomly selected students in 10 secondary schools using a self administered pre-tested questionnaire. Median age of participants was 17 years (15-19 years). Two-thirds (67.4\%) of the respondents had adequate level of knowledge on family planning services (FPS) and the most popular source of information was the radio $(65.8 \%)$. Being in a lower class $\left(\chi^{2}=8.6 ; P<0.02\right)$ and attending co education schools $\left(\chi^{2}=12.9 ; P<0.001\right)$ were predictors of inadequate level of knowledge on FPS. Most, $71.2 \%$ (225/316) respondents reported that FPS should not be used by adolescents and mentioned several reasons against its use. Less than $6 \%(18 / 316)$ of all respondents had used FPS in their lifetime, with $44.4 \%(8 / 18)$ in the past month, $33.3 \%(6 / 18)$ in the past year, and $22.3 \%(4 / 18)$ in the past 5 years. In conclusion, most secondary school students in Hai District do not utilize family planning services despite of adequate level of knowledge on FPS. Interventions to improve utilization of FPS among secondary school students should address barriers to low utilization of FPS mentioned in this study.
\end{abstract}

Keywords: family planning, knowledge, attitude, practice, adolescents, students, Tanzania

\section{Introduction}

According to United Nations Population Fund, family planning services are defined as the right of all couples and individual to decide freely and responsibly the number and spacing of their children and to have the information and means to do so. Indeed, family planning services (FPS) are regarded as a basic human right to attain the highest standard of sexual and reproductive health, free of discrimination, coercion and violence (UNFPA, 2003). Globally, family planning services are an essential element of reproductive health care and have saved the lives and protected the health of millions of women and children (UNFPA, 2003). However, family planning services are facing a complicated process, entangled in social, political, moral and cultural network in many African countries, including Tanzania (Richey, 2008). For example, Tanzania is among the sub-Saharan African countries with the highest total fertility rate at 5.4 births per woman (TDHS, 2010). Indeed, high percentage of adolescent are sexually active and practice unsafe sex, consequently, the majority of them are highly vulnerable to sexual and reproductive health problems that include unwanted pregnancy, early child bearing , complications of unsafe abortions, and sexually transmitted infections, including HIV/AIDS (TDHS,2010).

Globally, adolescent girls are probably the most vulnerable group as they are victims of early marriage, early and frequent child bearing, unsafe abortions all of which lead to high morbidity and mortality (UNAIDS, 2011). In fact pregnancy complications and sexually transmitted diseases during adolescence can permanently affect the future reproductive capacity of the girls as well as the future of a nation (Paluku et al., 2009).

The recent Tanzania Demographic and Health Survey identified that $20 \%$ of adolescents aged 15 to 19 years were sexually active. In addition, girls (14\%) were three times more likely than boys ( $5 \%$ ) of being sexually active before the age of 15 years (TDHS, 2010). Furthermore, teenage girls in Tanzania have a HIV prevalence rate of $4 \%$, compared to boys (3\%) of the same age

\footnotetext{
*Correspondence: E-mail: biesein2007@gmail.com
} 
group. HIV/AIDS in Tanzania is primarily transmitted through unprotected sexual intercourse and youths accounts for over $60 \%$ of the new HIV infection (TDHS, 2010; UNAIDS, 2011 ).

Apart from the risk of HIV/AIDS infection, adolescent girl's experiences several social consequences of unwanted pregnancies, such as early marriages and child bearing, expulsion from schools, domestic violence or abandonment from parents and peers alike (Paluku et al., 2009 ; Rondini \& Krugu,2009). A national survey conducted in Tanzania, observed that almost a quarter of young women age 15-19 are already married, and are pregnant or already have children (TDHS, 2010).

The HIV/AIDS pandemic has helped raise public awareness on the importance of adolescents' health since they are at the centre of the pandemic in terms of transmission, impact, and potential for changing the attitude and behaviour that underlie the disease (Toroitich-Ruto, 2004; UNICEF, 2006; Kirby, 2009; Upreti et al., 2009). However, adolescents sexual behaviour is a complex issue influenced by numerous variables, such as individual desire, social and cultural relationships, environmental and economic dynamics (Njau et al., 2006; Ochieng et al., 2011). Their socio-demographic characteristics (Kibret, 2003; Upreti et al., 2009), perception of peer behaviours (Stone et al., 2003; Mahat et al., 2006; Puri, 2006), level of knowledge and their attitudes towards their sexual and reproductive health (Rondini \& Krugu, 2009) may impact greatly on whether or not they have sex, the types of sexual relationships they form and utilization of family planning services (UNICEF, 2006).

Around the world, successful reproductive health programmes among adolescents are those that equip adolescents with knowledge, skills and attitudes that will keep them safe of consequences of unwanted pregnancies before they become sexually active(Oni et al., 2005; Paluku et al., 2009). In 2003, the government of Tanzania in recognition of the vulnerability of the youth prepared a National Policy Guidelines for Reproductive and Child Health Services, which aims at provision of reproductive health services and reproductive health education in schools (MoH, 2003).

Since most adolescents in Tanzania are sexually active and experience consequences of unprotected sexual intercourse, particularly girls, the objective of this study was to determine the knowledge, attitude and practices of secondary school students on family planning services. The findings will be useful in providing information to adolescents so that they develop attitudes, values and skills needed to achieve behavioural changes necessary to protect themselves and their peers from consequences related to unwanted pregnancy and sexually transmitted infections, including HIV/AIDS.

\section{Materials and Methods}

\section{Study site and subjects}

This was a descriptive cross sectional study conducted between April and June 2011 among 316 secondary school students in Hai District in northern Tanzania. Hai District, which is among six districts in Kilimanjaro region, has a population of 197,251 and adolescents aged 15 -24 years are 57,791 (31\%) of the total population (URT, 2003). Secondary Education system (SES) in Tanzania consists of two tiers. The first tier is ordinary level of four years post primary education (Form IIV). The second tier is advance level, which is two years post O-level (MoEVT, 2011). Hai district had 42 Secondary schools, with a total population of 13,629 students (male 6,287 (46\%) vs. female 7,342 (54\%). Of the 42 secondary schools 28(66.6) were public, and 14 (33.4) were private owned.

The sample size was calculated by adopting the proportion of $25.3 \%$ of level of knowledge on family planning services among adolescent's in secondary schools in Tanzania (Mwaikambo, 2005). A maximum likely error of 5\% with a $95 \%$ confidence interval was used. An allowance of $10 \%$ was estimated for the possible non-response. 


\section{Sampling procedure}

A multistage random sampling method was used as follows: All secondary schools in Hai district formed the primary sampling frame and were clustered according to boys only, girls only and co education secondary schools. The researchers purposively sampled 1 boys' school, 2 girls' schools and 6 co-education schools and a total of 10 schools were sampled. Individual students were recruited into the study using systematic random sampling, whereby every stream in a school formed a secondary sampling frame. Thereafter, the sampling interval was calculated based on a $10 \%$ of the school population. The result was then divided by the number of the streams in the school to determine the sample size per class. The sampling interval ( $n$ ) was then calculated by dividing the number of students in a stream by the sample size. The first student was selected blindly using a table of random numbers after which the remaining students were selected at regular intervals $(n)$ from the secondary sampling frame. This process was continued per stream until the required school sample size was achieved.

\section{Data collection}

Data was collected using a pre-tested self-administered questionnaire to elicit response on demographic characteristics; knowledge, attitude and practices of adolescents on family planning services. The questionnaire was adopted from a study done by Mwaikambo (2005) in Dar es Salaam and modified to suit the objectives of this study. Students' ages were obtained from the school registers during the day of the survey, before they were placed in the secondary sampling frame.

\section{Data analysis}

The questionnaires were edited for accuracy, completeness and uniformity then coded. Coding involved the categorization and quantification of data by assigning numerical values to the various categories in order to facilitate the statistical representation of data. The quantified data were then transferred to Statistical Package of Social sciences (SPSS version 13) computer package for data analysis. A two-tailed significance level was used since the direction of association between variables was not known in advance. Data was analyzed at the 0.05 level of significance.

\section{Ethical consideration}

Information about the study was explained to participants' and informed written consents were sought from each student (18-19 years old) or their guardians/parents (15-17 years old). Ethical clearance for the study was obtained from the Kilimanjaro Christian Medical University College Ethics Committee. Permission to conduct the study was sought from Hai District Medical Officer and District Education Officer, and Principals of the selected schools. Code numbers were used instead of names to ensure confidentiality. Participation was voluntary and participants had the right to withdraw from the study at any time.

\section{Results}

\section{Socio-demographic characteristics of respondents}

A total of 316 students were included in the study, comprising of equally distribution of female and male participants. Most participants, 248 (78.5\%) were aged between 15 and 17 years and 219 (69.3\%) were Christians (Table 1). Students in Year 1 were, 31 (9.8\%), Year II, 135 (42.7\%), Year III, $103(32.6 \%)$ and Year IV, 47 (14.9\%). 
Table 1: Socio-demographic characteristics of respondents $(n=316)$

\begin{tabular}{llll}
\hline Variable & Response & Frequency & Percent \\
\hline Sex & Male & 158 & 50.0 \\
& Female & 158 & 50.0 \\
Age & $15-17$ & 248 & 78.5 \\
& $18-19$ & 68 & 21.5 \\
Education level & Year 1 & 31 & 9.8 \\
& Year 2 & 135 & 42.7 \\
& Year 3 & 103 & 32.6 \\
& Year 4 & 47 & 14.9 \\
\hline
\end{tabular}

\section{Source of information on family planning services}

For both male and female student, the most popular source of information was radio ( $47.2 \%)$, followed by reading newspapers, (21.8\%), television (18.0\%), through friends (11.1\%), and others sources (4.1\%) (Figure 1).

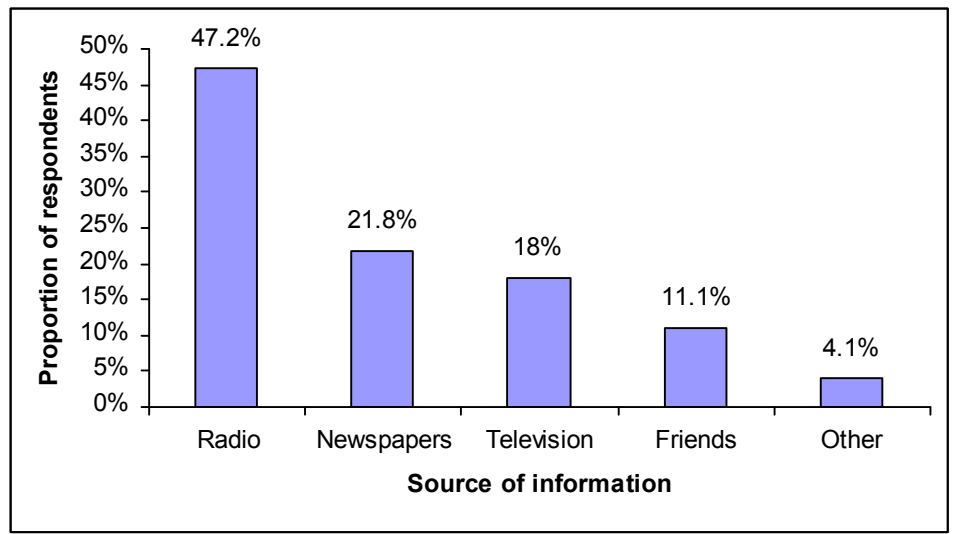

Figure 1: Sources of information on family planning services

\section{Knowledge on family planning services}

More than two third, $213(67.4 \%)$ of respondents who participated in this study had adequate level of knowledge on family planning services compared to 103 (32.6\%) who had inadequate level of knowledge (Table 2). Being in a lower class compared to a higher class was associated with inadequate knowledge on family planning services, and the difference was found to be statistically significant ( $41.9 \%$ vs. $16.7 \%$; $p<0.02$ ). Students from co education schools were more likely to have inadequate knowledge compared to those from non co-education schools, and the difference was statistically significant ( $42.4 \%$ vs. $22.8 \%$; $P<0.0001)$.

\section{Attitude towards family planning services}

Out of 316 respondent interviewed, $239(75.6 \%)$ thought that the right place for them to access family planning services is a health care facility, while 77 (24.4\%) mentioned anywhere outside the health facility can provide family planning services. Reasons mentioned against the use of family planning services among adolescents were: causes infertility ( $54.8 \%)$, followed by damage the uterus (48.1\%), reduces sexual pleasure (32.2\%),promotes sexual promiscuity (29\%), causes diseases of the reproductive organs (28.3\%),multiple sexual partnerships (26.8 \%),cause severe bleeding (21.5\%),and causes death (14.6\%) (Table 3). 
Table 2: Relationship between level of knowledge on family planning services and socio- demographic characteristics $(n=316)$

\begin{tabular}{|c|c|c|c|c|c|}
\hline \multirow[t]{2}{*}{ Variable } & \multirow[t]{2}{*}{ Response } & \multirow[t]{2}{*}{ Total } & \multicolumn{2}{|c|}{ Level of knowledge } & \multirow[t]{2}{*}{ P-value } \\
\hline & & & Adequate & Inadequate & \\
\hline \multirow[t]{2}{*}{ Sex } & Male & 158 & $105(65.8)$ & $53(34.2)$ & \\
\hline & Female & 158 & $108(68.9)$ & $50(31.1)$ & 0.317 \\
\hline \multirow[t]{2}{*}{ Age } & $15-17$ & 248 & $162(65.3)$ & $86(34.7)$ & \\
\hline & $18-19$ & 68 & $51(75.0)$ & $17(25.0)$ & 0.085 \\
\hline \multirow[t]{4}{*}{ Education level } & Year 1 & 31 & $18(58.1)$ & $13(41.9)$ & \\
\hline & Year 2 & 135 & $83(60.7)$ & $52(39 \cdot 3)$ & \\
\hline & Year 3 & 103 & $73(71.6)$ & $30(28.4)$ & \\
\hline & Year 4 & 47 & $39(83.3)$ & $8(16.7)$ & 0.016 \\
\hline \multirow[t]{2}{*}{ Type of school } & Either boys or Girls & 158 & $122(77.2)$ & $36(22.8)$ & \\
\hline & Both boys and Girls & 158 & $91(57.6)$ & $67(42.4)$ & 0.0001 \\
\hline
\end{tabular}

\section{Practices on family planning services}

Of the 316 respondents, $187(59.2 \%)$ were encouraged to use family planning services by their parents compared with 37(11.7\%) who were encouraged by their religious leaders. However, only $5.6 \%(18 / 316)$ of respondents had sought family planning services in their lifetime. Females were more likely than males to report contraceptive use ( $55.6 \% \mathrm{vs} .44 .4 \%$ ). Out of 18 respondents, 8 (44 $.4 \%)$ reported that they sought family planning services whenever they planned to have sex. Of the 18 respondents, $8(44.4 \%)$ seek family planning services in the past month, $6(33.3 \%)$ in the past one year and, $4(22.3 \%)$ in the past 5 years respectively. The types of contraceptives used are shown in Figure 2. The most common contraceptive used by males was the condom (100\%), while among females it was the injection (30\%).

Table 3: Reasons against the use of family planning services among adolescents $(n=316)$

\begin{tabular}{lll}
\hline Reason against family planning & Number & Percent \\
\hline Cause infertility & 171 & 54.8 \\
Damage uterus & 151 & 48.1 \\
Reduces sexual pleasure & 101 & 32.2 \\
Promotes sexual promiscuity & 91 & 29.0 \\
Causes diseases/conditions such as fistula, cancer, & 88 & 28.3 \\
urine retention & & \\
Encourage multiple sexual partners & 82 & 26.8 \\
Cause severe bleeding & 67 & 21.5 \\
Cause death & 46 & 14.6 \\
\hline
\end{tabular}

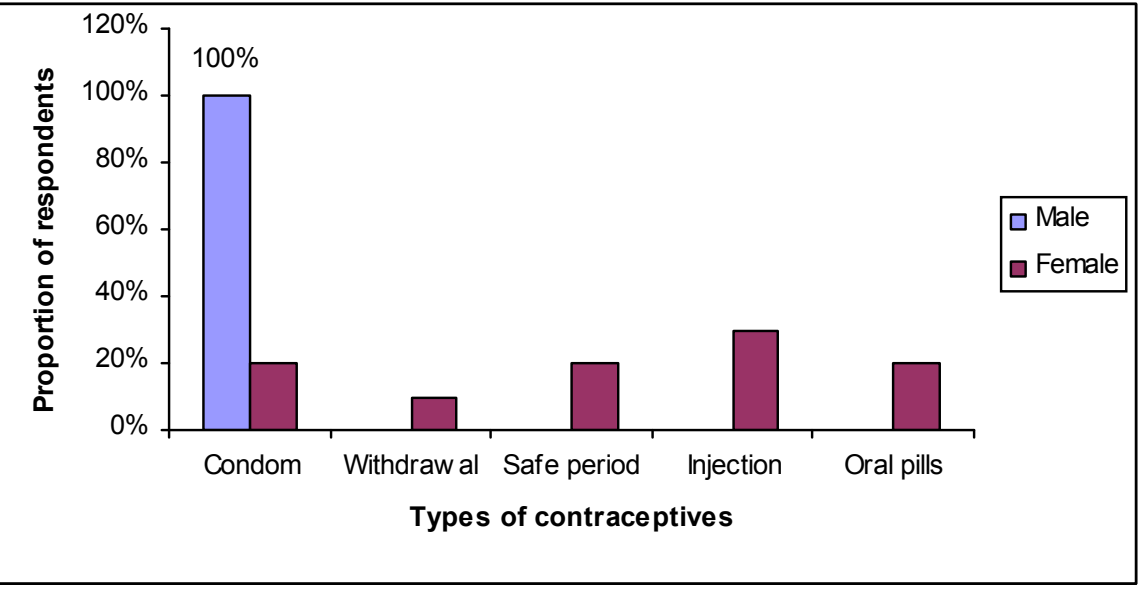

Figure 2: The proportion of respondents and types of contraceptives used 


\section{Discussion}

In this study, more than two-third of the students had adequate level of knowledge on family planning services with the majority being able to mention correctly two to three types of modern method of contraception. In addition, the most popular source of information on family planning services among study participants was through a radio. These observations concurs with results from a national survey which observed a high level of knowledge and mass media as a major source of information among 15-19 years old (Kamala \& Aboud,2006; TDHS.2010).

The most important predictors for inadequate level of knowledge on FPS in this study were being in a lower class and attending a co education schools. Similar results were observed in several studies in other settings (Toroitich-Ruto, 2004; Oni et al., 2005; Rondini \& Krugu, 2009; Nworah et al., 2009; Paluku et al., 2010). The most probable explanation is that older adolescents are more likely to be sexually experienced and more exposed to information on family planning services compared to their younger counterparts (Masatu et al., 2003; Oni et al., 2005; Paluku et al., 2010). The observation that students attending co education schools have inadequate level of knowledge compared to those in single education schools should be interpreted with caution. The most likely explanation to this observation could be the influence of selection bias of study participants, bearing in mind that most participants were from co education schools.

In this study, the majority of respondents thought that the right place to access FPS is in hospital compared to other settings outside the hospital. Other studies show that providing family planning services in a health facility can be a barrier to utilization (Guiella, 2007; Okech et al., 2011). Efforts to increase uptake of FPS should address the issue of appropriate place to provide such services to adolescents.

Even though the majority of students had adequate level of knowledge on FPS, most reported that family planning services should not be used by unmarried adolescents. More than half of respondents believed that family planning methods could cause infertility. Other reasons mentioned were also related to misconceptions about family planning methods. Similar findings on misconceptions about family planning methods have been reported from other studies elsewhere (Oni et al., 2005; Abiodun \& Balogun, 2009). Misconceptions about family planning methods are potential barriers to utilization and may lead young people to avoid use of available family planning methods and predispose themselves to the risk of reproductive tract illness, including HIV/AIDS (Mung'ong'o et al., 2010).

In our study, over half of respondents were encouraged to use family planning services by their parents and about one-fifth by their religious leaders. Similar findings have been observed in studies on the influence of significant others on positive health behaviours (Njau et al., 2006; Ochieng, 2011). The high proportions of parents compared to religious leaders in encouraging adolescents to use FPS reflect parent's knowledge on challenges faced by adolescents in their adolescence period and the need to protect them against the risk of unwanted pregnancy, child bearing and HIV/AIDS.

Utilization of family planning services was very low in our study population. Interestingly, four out of ten of the respondents in our study sought FPS when they plan to have sex. It is most likely that adolescent's have acquired information on the availability of FPS, such as condoms in such settings. However, with such low proportions, this observation may reflect the impact of misconceptions about FPS which have been documented in several studies among adolescents (Oni et al., 2005; Kamala \& Aboud, 2006; Njau et al., 2006; Ochieng et al., 2011).

In conclusion, most secondary school students in Hai District do not utilize family planning services despite of adequate level of knowledge on FPS. Interventions to improve utilization of FPS among secondary school students should address barriers to low utilization of FPS mentioned in this study. 


\section{Acknowledgements}

We are grateful to all secondary school respondents who participated in this study. This study received financial support from the Tanzania Ministry of Health and Social Welfare.

\section{References}

Abiodun, O.M. \& Balogun, O.R. (2009) Sexual activity and contraceptive use among young female students of tertiary educational institutions in Ilorin, Nigeria. Contraception Journal 79, 146-149.

Guiella, G. \& Madise, N.J. (2007) HIV/AIDS and Sexual-Risk Behaviours among Adolescents: Factors influencing the use of condoms in Burkina Faso. African Journal of Reproductive Health 11, 182-196.

Kamala, B.A. \& Aboud, S. (2006) Knowledge, attitudes and practices on HIV Prevention among Secondary School Students in Bukoba Rural, Kagera region, Tanzania. Dar es Salaam Medical Students Journal 14, 14-18.

Kirby, D., Rolleri, L. \& Wilson, M. (2009) Reducing pregnancy and risky behavior in teenagers Youth development programmes don't always work. British Medical Journal 359, 116-117.

Kibret, M. (2003) Reproductive health knowledge, attitude and practices among high school students in Bahir Dar, Ethiopia. African Journal of Reproductive Health 7, 39-45.

Mahat, G. \& Scoloven, M. (2006) Knowledge, attitude and belief among Nepalese adolescents. Journal of Advanced Nursing 53, 583-590.

Masatu, C.M., Kvale, G. \& Klepp, K. (2003) Frequency and perceived credibility of reported sources of reproductive health information among primary school adolescents in Arusha, Tanzania. Scandinavian Journal of Public Health 31, 216-223.

MoEVT (2011) Education departments: Secondary education. Ministry of Education and Vocational Training, Dar es Salaam, Tanzania.

$\mathrm{MoH}$ (2003) National Policy Guideline for Reproductive and Child Health services. Ministry of Health, Dar es Salaam, Tanzania.

Mung'ong'o, S.G. Mugoyela, V. \& Kimaro, B.(2010) Knowledge, attitude and practice on contraceptive use among secondary school students in Dar es Salaam, Tanzania. East and Central African Journal of Pharmaceutical Sciences 13, 43-49.

Mwaikambo, S.A. (2005) Modern Contraceptive Use among Secondary School Youths in Ilala Municipality, Tanzania. MPH Dissertation, Tumaini University, Tanzania.

Njau, B. Mtweve, S. Barongo, L. Manongi, R. Chugulu, J. Mwampeta, S. Kiwale, B. \& Jalipa, J. (2006) The influence of peers and other significant persons on sexuality and condom use among young adults in Northern Tanzania. African Journal of AIDS Research 5, 33-40.

Nworah, J.A., Sunday, U.M., Joseph, O.U., Monday, O.O. \& Josephat, C.C. (2009) Knowledge, attitude and practice of emergency contraception among students in tertiary schools in Anambra State southeast Nigeria. International Journal of Medicine and Medical Sciences 2, 1-4.

Ochieng, M.A., Kakai, R. \& Abok, K. (2011) Knowledge, attitude and practice of condom use among secondary schools students in Kisumu District, Nyanza Province. Asian Journal of Medical Sciences 3, 32-26.

Okech, T.C., Wawire, N.W. \& Mburu, T.K. (2011) Contraceptive use among women of reproductive age in Kenya's City Slums. International Journal of Business and Social Science 2, 22-43.

Oni, T.E., Prinsloo, E.A.M., Nortje, J.D. \& Joubert, G. (2005) High school students' attitudes, practices and knowledge of contraception in Jozini, KwaZulu-Natal. South African Family Practice 47, 54-57. 
Paluku, L.J., Mabunza, L.H. \& Maduna, P.M.H. (2010) Knowledge and attitude of schoolgirls about illegal abortions in Goma, Democratic Republic of Congo. African Journal of Primary Health Care \& Family Medicine 2, Art.\# 78 doi: 10.4102/phcfm.v2i1.78.

Puri, M. \& Cleland, J. (2006) Sexual behaviour and perceived risk of HIV/AIDs among young migrant factory workers in Nepal. Journal of Adolescent Health 38, 237-246.

Richey, L.A. (2008) Population Politics and Development: From the Policies to the Clinics. Fountain Publishers Ltd, Kampala Uganda 2nd Edition, 1-26.

Rondini, S. \& Krugu, J.K. (2009) Knowledge, Attitude and Practices Study on Reproductive Health among Secondary School Students in Bolgatanga Upper East Region, Ghana. African Journal of Reproductive Health 13, 51-66.

Stone, N., Ingham, R. \& Simkhanda, P. (2003) Knowledge on sexual health issues among unmarried young people in Nepal. Asia-Pacific Population Journal 18, 33-54.

Toroitich-Ruto, C. (2004) The effect of HIV/AIDS on sexual behaviour of young people in Kenya. Family Health International Report. Retrieved from: http:data.unaids.org/Publications/IRC-pub01/jc010-impactyoungpeople_en.pdf (Accessed on January 6, 2012).

UNAIDS (2011) Report on the Global AIDS Epidemic, 2011. Geneva.

UNFPA (2003) The State of World Population 2003. Making 1 Billion Count: Investing in Adolescents' Health and Rights. Geneva, United Nations Population Fund (UNFPA).

UNICEF (2006) HIV and AIDS Knowledge, Attitudes, Practices and Behaviour Study in Namibia. Retrieved from: http://www. nied. edu. na/publications/aids/UNICEF \% $20 \mathrm{Nam}$ 2006_HIV, (Accessed on: Jan 6, 2012).

Upreti, D., Regmi, P., Pant, P. \& Simkhada, P. (2009) Young people's knowledge, attitude, and behaviour on STI/HIV/AIDS in the context of Nepal: A systematic review. Kathmandu University Medical Journal 7, 383-391.

URT (2003) Population and Housing Census General Report. General Census Office. National Bureau of Statistics. President's Office, Planning and Privatization. Government Printers, Tanzania. 